Pacific Journal of Mathematics

FIXED POINTS AND CHARACTERIZATIONS OF CERTAIN 


\title{
FIXED POINTS AND CHARACTERIZATIONS OF CERTAIN MAPS
}

\author{
ChI Song Wong
}

Let $T$ be a self map on a metric space $(X, d)$ such that

$$
d(T(x), T(y)) \leqq(d(x, T(x))+d(y, T(y)) / 2, \quad x, y \in X .
$$

It is proved that: (a) $T$ has a fixed point if $T$ is continuous and $X$ is weakly compact convex subset of a Banach space. (b) All such $T$ which have fixed points can be explicitly determined in terms of $d$. Related results are obtained.

1. Introduction. In [7], [8], [9], [10], [11], R. Kannan considered the following family of self maps $T$ on a (nonempty) complete metric space $(X, d)$ :

$$
d(T(x), T(y)) \leqq \frac{1}{2}(d(x, T(x))+d(y, T(y))), \quad x, y \in X .
$$

He obtained a number of results of the following type: $T$ has a (unique) fixed point if $X$ is a weakly compact convex subset of a reflexive Banach space $B$ and for each closed convex subset $H$ of $X$ with $T(H) \subset H$ and $\delta(H)>0$,

$$
\sup \{d(y, T(y)): y \in H\}<\delta(H),
$$

where $d$ is the metric induced by the norm \|\| on $B$ and $\delta(H)$ is the diameter of $H$. Suppose now that $X$ is a weakly compact convex subset of a Banach space $B$ and $T$ is a self map on $X$ which satisfies (1). P. Soardi [17, Theorems I, II] proved that $T$ has a fixed point if either $X$ has normal structure [3] or $T$ has diminishing orbital diameters [2]. In this paper, the following results are obtained: (a) $T$ has a fixed point if it is continuous (with respect to the strong topology). In fact, $T$ has a fixed point if it is continuous along line segments. It may be worthwhile to mention here that it is a wellknown open problem that the same conclusion holds for nonexpansive self maps on $X[1, \mathrm{p} .217]$. (b) $T$ has a fixed point if for any closed convex subset $H$ of $X$ with more than one point and $T(H) \subset H$,

$$
\inf \{d(T(y), y): y \in H\}<\delta(H) .
$$

It is obvious that this result generalizes the above results of Soardi and the above result of Kannan. (c) Let $T$ be a self map on $X$ such that there exist $a_{1}, a_{2}, a_{3}, a_{4}, a_{5}$ in $[0,1]$ for which $a_{1}+a_{2}+a_{3}+$ $a_{4}+a_{5}=1$ and for all $x, y$ in $X$, 


$$
\begin{aligned}
d(T(x), T(y)) & \leqq a_{1} d(x, T(x))+a_{2} d(y, T(y))+a_{3} d(x, T(y)) \\
& +a_{4} d(y, T(x))+a_{5} d(x, y) .
\end{aligned}
$$

Then $T$ has a fixed point $u$ if for some $x_{0}$ in $X$, the sequence $\left\{x_{n}\right\}$, where $x_{n+1}=\left(x_{n}+T\left(x_{n}\right)\right) / 2$, converges to $u$. Note that by calculating $(d(T(x), T(y))+d(T(y), T(x))) / 2$ through (3), one may assume that $a_{1}=a_{2}$ and $a_{3}=a_{4}$. Thus when $a_{3}=a_{4}=a_{5}=0, T$ satisfies (1) if it satisfies (3). Also, (3) is satisfied if $T$ is nonexpansive. Serious consideration of those $T$ which satisfy (3) with $a_{1}=a_{2}=a_{3}=a_{4}=0$ was started by M. Edelstein [5]. In [14], [15], and [16], S. Reich considered those $T$ which satisfy (3) with $a_{3}=a_{4}=0$ and thus combined in a natural way, those maps investigated by Edelstein and Kannan. Recently, G. Hardy and T. Rogers [6] considered those maps which satisfy (3) with the possibility that none of the coefficients $a_{i}$ is zero.

For the interest of the reader, we pose the following statement: Every self map $T$ on a weakly compact convex subset $X$ of a Banach space has a fixed point if

$$
\|T(x)-T(y)\| \leqq \frac{1}{2}(\|x-T(x)\|+\|y-T(y)\|), \quad x, y \in X .
$$

From (a), (b), and (c), a counter example, if exists, would be difficult to construct.

Let $T$ be a self map on a metric space $(X, d)$ which satisfies (1). Once one succeeds in proving that $T$ has a fixed point, it is possible to characterize such $T$ by its fixed point. Because of this observation, the family of all self maps $T$ on a metric space $(X, d)$ which have a fixed point and which satisfy (1) can be found explicitly. As an example, the family of all such self maps $T$ on the unit interval is illustrated. There are exactly $2^{c}$ such maps, where $c$ is the cardinal of the real line.

2. Fixed point theorems. Let $T$ be a self map on a convex subset $X$ of a normed linear space. $T$ is continuous along line segments if for any $x, y$ in $X,\left\{T\left(x_{t}\right)\right\}$ converges to $T(x)$ as $t$ tends to 0 , where $x_{t}=(1-t) x+t y, t \in(0,1)$. Thus $T$ is continuous along line segments if $T$ is continuous.

THEOREM 1. Let $X$ be a (nonempty) weakly compact convex subset of a normed linear space. Let $T$ be a self map on $X$ which is continuous along line segments and satisfies

$$
\|T(x)-T(y)\| \leqq(\|x-T(x)\|+\|y-T(y)\|) / 2, \quad x, y \in X .
$$

Then $T$ has a unique fixed point in $X$. 
Proof. By Zorn's lemma, there exists a minimal nonempty weakly compact convex subset $H$ of $X$ such that $T(H) \subset H$. Let $x \in H$, $r=\|x-T(x)\|$. It suffices to prove that $r=0$. Consider

$$
W=\{y \in H:\|y-T(y)\| \leqq r\} \text {. }
$$

Since $x \in W, W \neq \varnothing$. Since $\left\|T^{2}(z)-T(z)\right\| \leqq\|T(z)-z\|$ for each $z$ in $X, T(W) \subset W$. Let $V$ be the closure of the convex hull of $T(W)$. We shall prove that $V \subset W$. Let $v \in V$ and $\varepsilon>0$. Then there exist $y_{1}, y_{2}, \cdots, y_{n}$ in $W$ and $t_{1}, t_{2}, \cdots, t_{n}$ in $[0,1]$ such that $\sum_{i=1}^{n} t_{i}=1$ and

$$
\left\|v-\sum_{i=1}^{n} t_{i} T\left(y_{i}\right)\right\|<\varepsilon .
$$

Thus

$$
\begin{aligned}
&\|v-T(v)\| \leqq \\
&\left|v-\sum_{i=1}^{n} t_{i} T\left(y_{i}\right)\|+\| \sum_{i=1}^{n} t_{i} T\left(y_{2}\right)-T(v)\right| \mid \\
&<\varepsilon+\sum_{i=1}^{n} t_{i}\left\|T\left(y_{i}\right)-T(v)\right\| \\
& \leqq \varepsilon+\left(\sum_{i=1}^{n} t_{i}\left(\left\|y_{i}-T\left(y_{i}\right)\right\|+\|v-T(v)\|\right)\right) / 2 \\
& \leqq \varepsilon+(r+\|v-T(v)\|) / 2 .
\end{aligned}
$$

So $\|v-T(v)\| \leqq 2 \varepsilon+r$. Since $\varepsilon$ is arbitrarily chosen, $\|v-T(v)\| \leqq r$, i.e., $v \in W$. Thus $V \subset W$. So

$$
T(V) \subset T(W) \subset V .
$$

By minimality of $H, V=H$. So $W=H$. Since $x$ is arbitrarily chosen, it follows from $W=H$ that $\|z-T(z)\|=r$ for all $z$ in $H$. Now let $y=T(x)$. Then

$$
\begin{aligned}
r= & \|(1-t) T(x)+t T(y)-T((1-t) T(x)+t T(y))\| \\
\leqq & (1-t)\|T(x)-T((1-t) T(x)+t T(y))\| \\
& +t\|T(y)-T((1-t) T(x)+t T(y))\| \\
\leqq & \frac{(1-t)}{2}(\|x-T(x)\|+\|(1-t) T(x)+t T(y) \\
& -T((1-t) T(x)+t T(y)) \|) \\
& +\frac{t}{2}(\|y-T(y)\|+\|(1-t) T(x)+t T(y) \\
& -T((1-t) T(x)+t T(y)) \|) \\
\leqq & \frac{1-t}{2}(r+r)+\frac{t}{2}(r+r)=r .
\end{aligned}
$$

Therefore, all the above inequalities are equalities. So 


$$
\|T(y)-T((1-t) T(x)+t T(y))\|=r .
$$

Since $T$ is continuous along line segments, we have by letting $t$ tend to 0

$$
\left\|T(y)-T^{2}(x)\right\|=r .
$$

Since $y=T(x), r=0$.

THEOREM 2. Let $X$ be a weakly compact convex subset of a Banach space $B$. Let $T$ be a self map on $X$ such that

$$
\|T(x)-T(y)\| \leqq(\|x-T(x)\|+\|y-T(y)\|) / 2, \quad x, y \in X .
$$

Suppose that for any closed convex subset $H$ of $X$ with $T(H) \subset H$ and $\delta(H)>0$,

$$
\inf \{\|y-T(y)\|: y \in H\}<\delta(H) .
$$

Then $T$ has a unique fixed point.

Proof. Construct $H$ as in the proof of Theorem 1. Suppose to the contrary that $\delta(H)>0$. By hypothesis, there exists $x$ in $H$ such that

$$
r \equiv\|x-T(x)\|<\delta(H) .
$$

Construct $V$ as in the proof of Theorem 1. It was proved that $V=W=H$ and $r=\|y-T(y)\|$ for each $y$ in $H$. Let $u, v \in H$. Then

$$
\begin{aligned}
\|T(u)-T(v)\| & \leqq(\|u-T(u)\|+\|v-T(v)\|) / 2 \\
& =(r+r) / 2=r .
\end{aligned}
$$

So $\delta(T(H)) \leqq r$. Thus

$$
\delta(H)=\delta(V)=\delta(T(W)) \leqq r<\delta(H),
$$

a contradiction.

We owe the above argument to Kannan [11] and Soardi [17]. Variants of such argument were used in [4] by R. DeMarr and were later refined by W. A. Kirk [12] for nonexpansive mappings. Then they were used in numerous other articles, e.g., [1], [2], and [13]. We would like to emphasize here that even for reflexive Banach spaces, our results are more general than the corresponding results of Kannan [Theorems 1 and 2, 11].

Theorem 3. Let $X$ be a convex subset of a normed linear space $B$. Let $T$ be a self map on $X$. Suppose that there exist $a_{i}, i=$ $1,2,3,4,5$, in $[0,1]$ such that $\sum_{i=1}^{5} a_{i}=1$ and for all $x, y$ in $X$, 


$$
\begin{aligned}
\|T(x)-T(y)\| \leqq & a_{1}\|x-T(x)\|+a_{2}\|y-T(y)\|+a_{3}\|x-T(y)\| \\
& +a_{4}\|y-T(x)\|+a_{5}\|x-y\| .
\end{aligned}
$$

Let $x_{0} \in X, t \in(0,1)$ and $x_{n+1}=(1-t) x_{n}+t T\left(x_{n}\right)$ for each integer $n \geqq 0$. Suppose that the sequence $\left\{x_{n}\right\}$ converges to a point $u$ in $X$. Then $u$ is a fixed point of $T$.

Proof. Let $n \geqq 0$. Then

$$
\begin{aligned}
\left\|x_{n+1}-T(u)\right\| & =\|(1-t)\left(x_{n}-T(u)+t\left(T\left(x_{n}\right)-T(u)\right) \|\right. \\
& \leqq(1-t)\left\|x_{n}-T(u)\right\|+t\left\|T\left(x_{n}\right)-T(u)\right\| .
\end{aligned}
$$

By hypothesis,

$$
\begin{aligned}
\left\|T\left(x_{n}\right)-T(u)\right\| \leqq & a_{1}\left\|x_{n}-T\left(x_{n}\right)\right\|+a_{2}\|u-T(u)\| \\
& +a_{3}\left\|x_{n}-T(u)\right\|+a_{4}\left\|u-T\left(x_{n}\right)\right\| \\
& +a_{5}\left\|x_{n}-u\right\| .
\end{aligned}
$$

Since $\left\{x_{m}\right\}$ converges to $u$, and $x_{n+1}-x_{n}=t\left(T\left(x_{n}\right)-x_{n}\right),\left\{T\left(x_{m}\right)-x_{m}\right\}$ converges to 0 . Thus $\left\{u-T\left(x_{m}\right)\right\}$ converges to 0 . From (5) and (6), we have by letting $n$ tend to $\infty$,

$$
\begin{aligned}
& \|u-T(u)\| \\
\leqq & (1-t)\|u-T(u)\|+t\left(a_{2}\right)\|u=T(u)\|+a_{3}\|u-T(u)\| \\
= & \left((1-t)+t\left(a_{2}+a_{3}\right)\right)\|u-T(u)\| .
\end{aligned}
$$

We may assume that $a_{1}=a_{2}$ and $a_{3}=a_{4}$. Thus $a_{2}+a_{3} \leqq 1 / 2$. So from (7),

$$
\|u-T(u)\| \leqq\left(1-\frac{1}{2} t\right)\|u-T(u)\| \text {. }
$$

Since $1-(1 / 2) t \in(0,1), T(u)=u$.

3. Examples. Let $a$ be a point in a metric space $(X, d) . \quad X_{a}$ will denote the set

$$
\left\{(x, y) \in X \times X: d(y, a) \leqq \frac{1}{2} d(x, y)\right\} .
$$

THEOREM 4. Let $T$ be a self map on a metric space. Then the following coditions are equivalent:

(a) Thas a fixed point and

$$
d(T(x), T(y)) \leqq(d(x, T(x))+d(y, T(y))) / 2
$$

for all $x, y$ in $X$. 
(b) There exists a in $X$ such that $T \subset X_{a}$, i.e.,

$$
d(T(x), a) \leqq d(x, T(x)) / 2, \quad x \in X .
$$

To see the use of Theorems 2 and 4 , let $T$ be a self map on the unit interval with the usual metric. Then $T$ satisfies (1) if and only if there exists $a$ in $X$ such that $T \subset X_{a}$. So in order to find all the maps considered by Kannan, it suffices to find all $X_{a}$ 's with $a$ in $X$. For illustration, we list $X_{0}, X_{1 / 4}, X_{1 / 2}, X_{3 / 4}, X_{1}$ as follows (the shaded parts): Thus $X_{a}$ is determined by the lines $x+y=2 a$ and
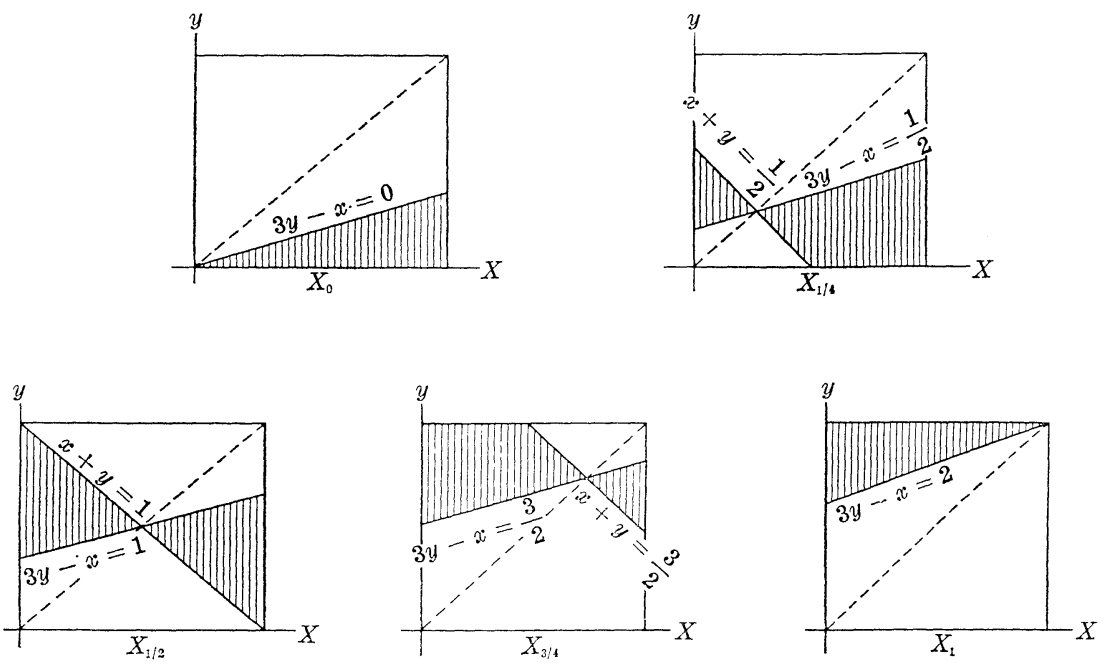

$3 y-x=2 a$ : If one cuts $X \times X$ along these lines, then $X_{a}$ is the closure (in $X \times X$ ) of the union of those parts which do not contain more than one point of the diagonal of $X \times X$.

Once it was difficult to construct enough examples of those maps considered by Kannan. Now it seems too easy to find a lot. It is then only natural to be more demanding. By looking at the above example where $X=[0,1]$, we find that it is difficult for a self map on $X$ which satisfies (1) to be surjective. In [18], it was proved that if $T$ is a self map on $[0,1]$ which satisfies $(1)$ and if $0,1 \in T[0,1]$, then $1 / 2$ is the fixed point of $T$. This result is an obvious consequence of Theorems 2 and 4 . For the interest of the reader, we list two more consequences of Theorems 2 and 4: (a) Let $T$ be a self map on $X=[0,1]$ such that $0,1 \in T([0,1)]$ and $T$ is not the identity map on $[0,1]$. Then the following conditions are equivalent: (i) $T$ satisfies (1). (ii) $T$ satisfies (3). (iii) For any $x, y \in X$,

$$
\begin{aligned}
& d(T(x), T(y)) \\
\leqq & \sup \{d(x, y),(d(x, T(x))+d(y, T(y))) / 2,(d(x, T(y))+d(y, T(x))) / 2\} .
\end{aligned}
$$


(b) Let $X$ be a regular polygon in the two dimensional Euclidean space. Then there exists a self map $T$ of $X$ onto $X$ which satisfies (1) if and only if $X$ has even number of sides.

Added in proof. Let $K$ be a closed convex subset of a Banach space $B . K$ has a close-to-normal structure if for any bounded closed convex subset $H$ of $K$ with $\delta(H)>0$, there exists $x$ in $H$ such that $\|x-y\|<\delta(H)$ for all $y$ in $H$. The following related results were announced by the author at the International Congress of Mathematicians in 1974. (a) $B$ has a close-to-normal structure if (1) $B$ is separable, (2) $B$ is strictly convex, or (3) $B$ is reflexive and for any sequence $\left\{x_{n}\right\}$ in $B,\left\{x_{n}\right\}$ converges to $x$ in $B$ whenever $\left\{x_{n}\right\}$ converges weakly to $x$ and $\left\{\left\|x_{n}\right\|\right\}$ converges to $\|x\|$. (b) A Hilbert space is isomorphic to a Banach space which has no close-to-normal structure if and only if it is separable. (b) together with Theorem 4 in Chi Song Wong, Proc. Amer. Math. Soc., 46 (1974), to appear, solve the problem we posed in the introduction of this paper. Related to (b), we mentioned here that all theorems for normal structure (=completely normal structure) in L. P. Belluce, W. A. Kirk and E. P. Steiner, Normal structure in Banach spaces, Pacific J. Math., 26 (1968) 433440 , can be modified to results for close-to-normal structure.

\section{REFERENCES}

1. L. P. Belluce and W. A. Kirk, Fixed-point theorems for families of contraction mappings, Pacific J. Math., 18 (1966), 213-217.

2. - Fixed-point theorems for certain classes of noonexpansive mappings, Proc. Amer. Math. Soc., 20 (1969), 141-146.

3. M. S. Brodskii and C. P. Milman, On the center of a convex set, Dokl. Akad. Nank SSSR, 59 (1948), 837-840.

4. Ralph DeMarr, Common fixed-point for commuting contraction mappings, Pacific J. Math., 13 (1963), 1139-1141.

5. M. Edelstein, On fixed and periodic points under contractive mappings, J. London Math. Soc., 37 (1962), 74-79.

6. G. Hardy and T. Rogers, A generalization of a fixed point theorem of Reich, Canad. Math. Bull., 16 (1973), 201-206.

7. R. Kannan, Some results on fixed points, Bull. Cal. Math. Soc., 60 (1968), 71-76.

8. - Some results on fixed points-II, Amer. Math. Monthly, 76 (1969), 405-408.

9. —_ Some results on fixed points-III, Fund. Math., 70 (1971), 160-177.

10. - Some results on fixed points-IV, Fund. Math., 74 (1972), 181-187.

11. - Fixed point theorems in reflexive Banach spaces, Proc. Amer. Math. Soc., 38 (1973), 111-118.

12. W. A. Kirk, A fixed point theorem for mappings which do not increase distances, Amer. Math. Monthly, 74 (1965), 1004-1006.

13. W. A. Kirk and W. D. Royality, Fixed point theorems for certain nonexpansive mappings, Illinois J. Math., 15 (1971), 656-663.

14. Simeon Reich, Some remarks concerning contraction mappings, Canad. Math. Bull., 14 (1971), 121-124. 
15. Simeon Reich, Kannan's fixed point theorem, Boll. Un. Math. Ital., 4 (1971), 1-11. 16. - Fixed points of contractive functions, Boll. Un. Math. Ital., 4 (1972), 26-42.

17. Paolo Soardi, Su un problema di punto unito di. S. S. Reich, Boll. Un. Math. Ital., 4 (1971), 841-845.

18. Chi Song Wong, Fixed points of certain self maps on an interval, Proc. Amer. Math. Soc., 42 (1974), 234-235.

Received March 28, 1973. This research was partially supported by the National Research Council of Canada Grant A8518.

UNIVERSITY OF WINDSOR 


\section{PACIFIC JOURNAL OF MATHEMATICS}

\section{EDITORS}

RICHARD ARENS (Managing Editor)

University of California

Los Angeles, California 90024

R. A. Beaumont

University of Washington

Seattle, Washington 98105
J. DugundJI

Department of Mathematics University of Southern California Los Angeles, California 90007

D. Gilbarg AND J. Milgram Stanford University

Stanford, California 94305

\section{ASSOCIATE EDITORS}
E. F. BECKENBACH
B. H. NeUmanN
F. WOLF
K. YOSHIDA

\section{SUPPORTING INSTITUTIONS}

UNIVERSITY OF BRITISH COLUMBIA CALIFORNIA INSTITUTE OF TECHNOLOGY

UNIVERSITY OF CALIFORNIA

MONTANA STATE UNIVERSITY

UNIVERSITY OF NEVADA

NEW MEXICO STATE UNIVERSITY

OREGON STATE UNIVERSITY

UNIVERSITY OF OREGON

OSAKA UNIVERSITY
UNIVERSITY OF SOUTHERN CALIFOF

STANFORD UNIVERSITY

UNIVERSITY OF TOKYO

UNIVERSITY OF UTAH

WASHINGTON STATE UNIVERSITY UNIVERSITY OF WASHINGTON

AMERICAN MATHEMATICAL SOCIET NAVAL WEAPONS CENTER 


\section{Pacific Journal of Mathematics}

\section{Vol. 54, No. 1 \\ May, 1974}

Ralph K Amayo, Engel Lie rings with chain conditions ..................

Bernd Anger and Jörn Lembcke, Hahn-Banach type theorems for hypolinear

functionals on preordered topological vector spaces ..................

Gregory Frank Bachelis and Samuel Ebenstein, On $\Lambda(p)$ sets ................

Harvey Isaac Blau, Indecomposable modules for direct products of finite

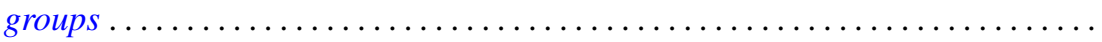

Larry Eugene Bobisud and James Calvert, Singular perturbation of a

time-dependent Cauchy problem in a Hilbert space ................

Walter D. Burgess and Robert Raphael, Abian's order relation and orthogonal

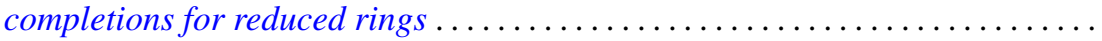

James Diederich, Representation of superharmonic functions mean continuous at

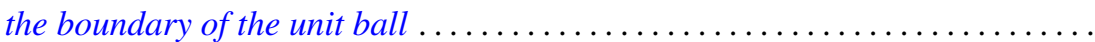

Aad Dijksma and Hendrik S. V. de Snoo, Self-adjoint extensions of symmetric

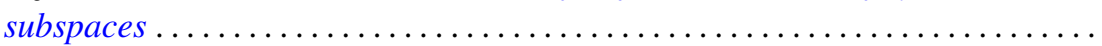

Gustave Adam Efroymson, A Nullstellensatz for Nash rings . . . . . . . . . . . . .

John D. Elwin and Donald R. Short, Branched immersions onto compact orientable surfaces . . . . . . . . . . . . . . . . . . . . . . . . .

John Douglas Faires, Comparison of the states of closed linear

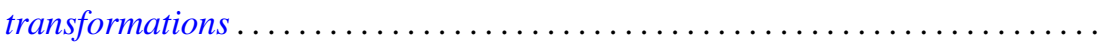

Joe Wayne Fisher and Robert L. Snider, On the von Neumann regularity of rings with regular prime factor rings .

Franklin Takashi Iha, A unified approach to boundary value problems on compact intervals

Palaniappan L. Kannappan and Che Tat $\mathrm{Ng}$, On functional equations connected with directed divergence, inaccuracy and generalized directed divergence

Samir A. Khabbaz and Elias Hanna Toubassi, The module structure of Ext $(F, T)$ over the endomorphism ring of $T$...

Garo K. Kiremidjian, On deformations of complex compact manifolds with boundary.

Dimitri Koutroufiotis, Mappings by parallel normals preserving principal

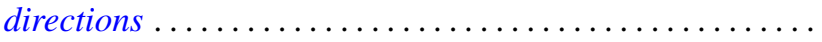

W. K. Nicholson, Semiperfect rings with abelian adjoint group

Norman R. Reilly, Extension of congruences and homomorphisms to translational hulls

Sadahiro Saeki, Symmetric maximal ideals in $M(G)$

Brian Kirkwood Schmidt, On the homotopy invariance of certain functors ...

H. J. Shyr and T. M. Viswanathan, On the radicals of lattice-ordered rings ...

Indranand Sinha, Certain representations of infinite group algebras ...

David Smallen, The group of self-equivalences of certain complexes ...

Kalathoor Varadarajan, On a certain problem of realization in homotopy

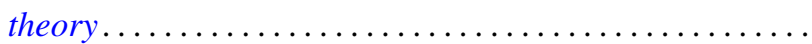

